\title{
ARTICLE
}

\section{Acaricidal activity of nishinda (Vitex negundo) leaf and gar- lic (Allium sativum) bulb extract against red spider mite, Oligonychus coffede (Acari: Tetranychidae) in tea plantations of Darjeeling hill, West Bengal, India}

\author{
Piu Banerjee ${ }^{1}$, Arghya Laha1, Indrani Samaddar ${ }^{1}$, Himani Biswas ${ }^{2}$, Debjani Sarkar ${ }^{3}$, Sovan \\ Roy $^{4}$, Goutam K. Saha ${ }^{5}$, Sanjoy Podder ${ }^{1 *}$

\begin{abstract}
${ }^{1}$ Allergology and Applied Entomology Research Laboratory, Department of Zoology, University of Burdwan, Bardhaman-713104, West Bengal, India

Department of Zoology, Krishnagar Government College, Krishnagar-741101, West Bengal, India

${ }^{3}$ Department of Zoology, APC Roy Government College, Siliguri-734010, West Bengal, India

${ }^{4}$ Department of Science and Technology and Biotechnology, Vigyan Chetana Bhavan, Kolkata-700064, West

Bengal, India

${ }^{5}$ Department of Zoology, University of Calcutta, Kolkata-700019, West Bengal, India
\end{abstract}

\begin{abstract}
The red spider mite, Oligonychus coffeae (Nietner) serves as a serious threat to the Darjeeling tea plantations affecting the quality of the leaves. Various plant extracts are currently being researched as an alternative to the chemical pesticides to control the red spider mites. In the present study, the leaves of Vitex negundo L. and the bulb of Allium sativum L. were analyzed for their acaricidal activity on the larval, nymphal and adult stages of the mite. Both the extracts were found to have potent activity against red spider mites and may prove to be potential acaricides in future.

Acta Biol Szeged 65(1):59-64 (2021)
\end{abstract}

\author{
KEY WORDS \\ Darjeeling \\ garlic bulb extract \\ Nishinda \\ Oligonychus coffeae \\ tea \\ ARTICLE INFORMATION
Submitted
11 February 2021.
Accepted
24 July 2021.
*Corresponding author
E-mail: skpzoo2@rediffmail.com
}

\section{Introduction}

Growing food and beverage crops in a sustainable way to obtain optimal yield and nutrition with sensible use of renewable resources while maintaining the biodiversity and soil fertility with least ecological disruption is a challenge for the farmers and associated stakeholders in the present decade. In this endeavor, cultivation of tea is no exception. In India, tea is grown in about 42.2-millionhectare land. Owing to the flavor and the quality, the tea originating from Darjeeling hills is highly preferred both in India and overseas.

More than one thousand arthropods have been recorded to feed on different parts of the tea plants (Chen and Chen 1989) all over the world. Among them, Oligonychus coffeae Nietner, the tea red spider mite, a major arthropod pest that attacks most cultivars in tea plantations of Darjeeling, India (Das 1965; Banerjee et al. 2020) played a significant role for causing damage to tea. The red spider mite increased within a short period of time in the tea plantations due to its high reproductive capacity (Das 1959a,1959b, 1960). Despite adopting several management strategies in the tea gardens of the Darjeeling hills, West Bengal, India, pest infestations are quite prevalent. Many of the tea gardens of Darjeeling hills have been using organic farming methods, with least use of the chemicals for regulation of the pests. Therefore, pest infestations increased leading to a decrease in the quality of tea produced (Bhujel 2016). This in turn leads to a decrease in export with a loss of millions of rupees in terms of revenue. Therefore, an enhanced management regime is required to combat the pest and pest related effects on the tealeaves.

Natural products from plants are an excellent source of pesticidal compounds, especially insecticides, as many plant species have evolved chemical protection from insects. Several classes of insecticides (e.g., the pyrethroids) are based on compounds from plants. During the last few years, during an increasingly intensive search by 
many research groups all over the world, the plant family Lamiaceae and Amaryllidaceae were identified as two of the most promising sources with insect-control properties (Ho et al. 1996; Uritu et al. 2018). In particular, some members of the genera Vitex and Allium were found to be highly effective against insects and mites (Yathiraj and Jagadish 1999; Attia et al. 2012). Unfortunately, information regarding efficacy of these two plant extracts to control mites is very scarce from India. Therefore, the present work is designed to evaluate the efficacy of these two plant extracts to control tea red spider mite (O. coffeae).

\section{Materials and methods}

\section{Rearing of red spider mite (0. coffeae)}

Mites were collected from different tea fields of Darjeeling and a continuous stock culture of $O$. coffeae has been maintained in rearing tray throughout the period of experiment in an incubator at $25 \pm 2{ }^{\circ} \mathrm{C}$ and $70-75 \%$ relative humidity $(\mathrm{RH})$.

\section{Preparation of plant extracts}

Two types of plant materials have been used for extract preparation: 1) leaves of nishinda (Vitex negundo L); 2) bulb of garlic (Allium sativum $\mathrm{L}$ ). The different concentrations ranging from 0.5 to $6.5 \mathrm{mg} / \mathrm{ml}(0.5,1,1.5,2,2.5,3,3.5$, $4,4.5,5,5.5,6$, and $6.5 \mathrm{mg} / \mathrm{ml}$ ) was obtained by diluting stock in $20 \mathrm{ml}$ distilled water. The procedures of extract preparation are as follows:

\section{Nishinda leaf extract (NLE)}

Healthy leaves were collected in zipper bags. These leaves were then washed with running water, dried for 5-6 days under shade and coarsely grounded. The powder derived from this process was subjected to extraction. $10 \mathrm{~g}$ of that powder were taken in a conical flask $(250 \mathrm{~mL})$, dipped in $100 \mathrm{ml}$ methanol, and allowed to stand overnight for extraction. The material was then filtered through Whatman no.1 filter paper and kept in an open Petri dish for complete evaporation. The extraction procedure was repeated for three times with the residues remaining in the filter paper. After completion of the evaporation, the sticky greenish residue found on Petri dish was scrapped out using a scalpel and treated as stock material for preparation of different concentrations.

\section{Garlic bulb extract (GBE)}

For preparation of GBE, the protective layer of garlic cloves was peeled out and $10 \mathrm{~g}$ of garlic was weighed, rinsed and crushed in a mixer grinder. The homogenized garlic was then taken in a conical flask $(250 \mathrm{ml})$, dipped in $100 \mathrm{ml}$ methanol and allowed to stand overnight for extraction. The material was then filtered through Whatman no.1 filter paper in a beaker $(250 \mathrm{ml})$ and kept in an open Petri dish for complete evaporation. The extraction procedure was repeated thrice with the residues remaining in the filter paper. After completion of the evaporation, a sticky white-yellowish residue was found on Petri dish and was scrapped out using scalpel. This was treated as stock material for preparation of different concentrations.

\section{Laboratory bioassay for acaricidal activity test on lar- vae, nymphs and adults}

In-vitro assay for control of mites were performed with different concentrations of plant extracts. All the assays were done in an incubator at $25 \pm 2{ }^{\circ} \mathrm{C}$ and $70-75 \% \mathrm{RH}$. Tealeaf discs of $8 \mathrm{~cm}$ diameter were dipped into different concentrations of both NLE and GBE for five minutes and then kept under a ceiling fan for drying. These leaf discs were placed with its dorsal surface up over the wet cotton taken in a Petri dish. Fifty healthy mites were then released on each treated leaf disc. The assay was replicated ten times for each concentration. Water treated leaves were taken as control. The leaves were observed under stereo-binocular microscope at every $24 \mathrm{~h}$ and the number of mites that survived was counted, for seven days consecutively.

Table 1. Larvicidal effects of the nishinda ( $V$. negundo) leaf extracts and garlic ( $A$. sativum) bulb extract on the larva of $O$. coffeae, at the median lethal concentrations $(\mathrm{mg} / \mathrm{mL})$. * $=$ P value significant.

\begin{tabular}{|c|c|c|c|c|c|c|c|c|c|c|c|c|c|c|}
\hline \multirow[b]{2}{*}{ Hours } & \multicolumn{7}{|c|}{ Nishinda (V. negundo) Median \pm SD } & \multicolumn{7}{|c|}{ Garlic (A. sativum) Median \pm SD } \\
\hline & 24 & 48 & 72 & 96 & 120 & 144 & 168 & 24 & 48 & 72 & 96 & 120 & 144 & 168 \\
\hline LC50-value & $3.04 \pm 0.10$ & $2.63 \pm 0.07$ & $2.09 \pm 0.12$ & $1.89 \pm 0.11$ & $1.72 \pm 0.11$ & $1.69 \pm 0.11$ & $1.56 \pm 0.34$ & $3.60 \pm 0.14$ & $3.19 \pm 0.13$ & $2.72 \pm 0.18$ & $2.29 \pm 0.19$ & $2.11 \pm 0.10$ & $1.93 \pm 0.14$ & $1.81 \pm 0.19$ \\
\hline Slope & $6.52 \pm 0.40$ & $4.57 \pm 0.53$ & $3.25 \pm 0.24$ & $3.01 \pm 0.34$ & $2.94 \pm 0.29$ & $2.84 \pm 0.55$ & $2.20 \pm 0.35$ & $6.18 \pm 0.58$ & $4.65 \pm 0.34$ & $3.06 \pm 0.30$ & $2.76 \pm 0.51$ & $2.74 \pm 0.49$ & $2.55 \pm 0.50$ & $2.62 \pm 0.32$ \\
\hline Intercept & $-3.12 \pm 1.89$ & $-1.95 \pm 0.22$ & $-1.04 \pm 0.13$ & $-0.82 \pm 0.11$ & $-0.73 \pm 0.11$ & $-0.49 \pm 0.32$ & $-0.53 \pm 0.18$ & $-3.57 \pm 0.32$ & $-2.34 \pm 0.15$ & $-1.29 \pm 0.14$ & $-0.96 \pm 0.13$ & $-0.80 \pm 0.58$ & $-0.74 \pm 0.19$ & $-0.70 \pm 0.19$ \\
\hline R-value & 0.99 & 0.99 & 0.91 & 0.88 & 0.78 & 0.87 & 0.83 & 0.97 & 0.98 & 0.95 & 0.91 & 0.89 & 0.88 & 0.91 \\
\hline P-value & $<0.0001 *$ & $<0.0001 *$ & $0.0016^{*}$ & $0.008^{*}$ & $0.0446 *$ & $0.0482 *$ & 0.0481 * & $<0.0001 *$ & $<0.0001 *$ & $<0.0001 *$ & $0.0013^{*}$ & $0.0062 *$ & $0.0168 *$ & $0.026^{*}$ \\
\hline t-test & \multicolumn{14}{|c|}{$t=14.80, d f=69, p<0.001^{*}$} \\
\hline
\end{tabular}


Table 2. Nymphicidal effects of the nishinda ( $V$. negundo) leaf extracts and garlic ( $A$. sativum) bulb extract on the larva of $O$. coffeae, at the median lethal concentrations $(\mathrm{mg} / \mathrm{mL})$. ${ }^{*}=\mathrm{P}$ value significant.

\begin{tabular}{|c|c|c|c|c|c|c|c|c|c|c|c|c|c|c|}
\hline \multirow[b]{2}{*}{ Hours } & \multicolumn{7}{|c|}{ Nishinda (V. negundo) Median \pm SD } & \multicolumn{7}{|c|}{ Garlic (A. sativum) Median \pm SD } \\
\hline & 24 & 48 & 72 & 96 & 120 & 144 & 168 & 24 & 48 & 72 & 96 & 120 & 144 & 168 \\
\hline LC50-value & $3.73 \pm 0.40$ & $3.29 \pm 0.06$ & $2.86 \pm 0.09$ & $2.56 \pm 0.16$ & $2.10 \pm 0.22$ & $2.23 \pm 0.47$ & $1.60 \pm 0.23$ & $4.14 \pm 0.09$ & $3.69 \pm 0.10$ & $2.92 \pm 0.11$ & $2.37 \pm 0.20$ & $2.05 \pm 0.12$ & $1.81 \pm 0.14$ & $1.33 \pm 0.12$ \\
\hline Slope & $8.28 \pm 0.55$ & $6.47 \pm 0.64$ & $4.47 \pm 0.79$ & $2.83 \pm 0.28$ & $2.55 \pm 0.18$ & $1.77 \pm 0.46$ & $1.79 \pm 0.34$ & $8.82 \pm 0.74$ & $6.06 \pm 0.60$ & $4.50 \pm 0.46$ & $3.11 \pm 0.27$ & $2.60 \pm 0.21$ & $2.23 \pm 0.26$ & $2.00 \pm 0.20$ \\
\hline Intercept & $-4.71 \pm 0.65$ & $-3.35 \pm 0.34$ & $-2.03 \pm 0.36$ & $-1.14 \pm 0.13$ & $-0.81 \pm 0.11$ & $-0.60 \pm 0.11$ & $-0.35 \pm 0.10$ & $-5.49 \pm 0.52$ & $-3.43 \pm 0.33$ & $-2.09 \pm 1.36$ & $-1.15 \pm 0.12$ & $-0.83 \pm 0.09$ & $-0.51 \pm 0.10$ & $-0.28 \pm 0.08$ \\
\hline$R$-value & 0.97 & 0.98 & 0.97 & 0.92 & 0.9 & 0.94 & 0.94 & 0.96 & 0.98 & 0.92 & 0.87 & 0.86 & 0.88 & 0.81 \\
\hline P-value & $0.0005^{*}$ & $<0.0001$ * & 0.0001 * & $0.0022 *$ & $0.0118^{*}$ & $0.0123^{*}$ & $0.0126 *$ & 0.0011 * & $<0.0001$ * & $0.0004 *$ & $0.0019 *$ & $0.006^{*}$ & $0.007 *$ & $0.026^{*}$ \\
\hline t-test & $\mathrm{t}=0.71, \mathrm{df}=$ & $69, p=0.48$ & & & & & & & & & & & & \\
\hline
\end{tabular}

\section{Statistical analysis}

In the present study, the efficiency of NLE and GBE has been evaluated at different concentrations $(0.5-6.5 \mathrm{mg} / \mathrm{ml})$ for seven days at $24 \mathrm{~h}$ interval against larval, nymphal and adult red spider mite and the data obtained from experiments were subjected to probit analysis (Finney 1971) to estimate $\mathrm{LC}_{50}$ value. The correlation between concentration of pesticides and probit value was estimated by linear regression. Unpaired t-test has been done to compare the toxicity level between different pesticides used. $\mathrm{P}<0.05$ was considered as significant. All the analysis was done using Prism Ver. 7 (Graph Pad Prism, San Diego, CA).

\section{Results}

\section{$\angle C_{50}$ of NLE and GBE for mite larva}

Table 1. shows the $\mathrm{LC}_{50}$ values for the NLE and GBE on larva stage of mite for $24,48,72,96,120,144$ and $168 \mathrm{~h}$ of experiment. Results according to probit analysis reveals that the lethal concentration $\left(\mathrm{LC}_{50}\right)$ of NLE to mite larva for 24, 48, 72, 96, 120, 144 and $168 \mathrm{~h}$ of exposure are $3.04,2.63,2.09,1.89,1.72,1.69$ and $1.56 \mathrm{mg} / \mathrm{mL}$ and that for GBE are 3.60, 3.19, 2.72, 2.29, 2.11, 1.93 and 1.81 $\mathrm{mg} / \mathrm{ml}$, respectively. A gradual reduction in slope function corresponding to an increase in the exposure time from 24 to $168 \mathrm{~h}$ has been observed. Observations on the upper and lower confidence limits show a decreasing trend from 24 to $168 \mathrm{~h}$. As NLE shows $\mathrm{LC}_{50}$ values which are significantly lower than GBE $(\mathrm{t}=14.80$, df $=69, \mathrm{p}<0.001)$, this revealed that NLE is a more potent larvicide than GBE. Values of correlation coefficient (R) for each time interval demonstrate (Table 1) that there is a positive correlation between concentration of pesticides and mortality of larvae, which is statistically significant.

\section{$L C_{50}$ of NLE and GBE for mite nymph}

The $\mathrm{LC}_{50}$ value for NLE and GBE on nymph stage of mite for $24,48,72,96,120,144$ and $168 \mathrm{~h}$ of experiment has been depicted in Table 2. Probit analysis explore that the $\mathrm{LC}_{50}$ values for NLE to O. coffeae (nymphs) were found to be $3.73,3.29,2.86,2.56,2.10,2.23$ and $1.60 \mathrm{mg} / \mathrm{ml}$ and for GBE the $\mathrm{LC}_{50}$ values are 4.14, 3.69, 2.92, 2.37, 2.05, 1.81 and $1.33 \mathrm{mg} / \mathrm{ml}$ for $24,48,72,96,120,144$ and $168 \mathrm{~h}$, respectively. Initially, NLE seemed to be more potent but with increasing exposure, GBE had lower $\mathrm{LC}_{50}$ values. A progressive decline in slope function corresponding to an increment in the exposure time from 24 to $168 \mathrm{~h}$ has been found. As the exposure time is raised, the contact acaricidal activity increased. The upper and lower confidence limits revealed a diminishing trend from 24 to $168 \mathrm{~h}$. Control with water shows no mortality of nymph. Correlation coefficient $(\mathrm{R})$ value against each hour indicates (Table 2) that there is a significant positive correlation between

Table 3. Adulticidal effects of the nishinda ( $V$. negundo) leaf extracts and garlic ( . sativum) bulb extract on the larva of $O$. coffeae, at the median lethal concentrations $(\mathrm{mg} / \mathrm{mL})$. * $=$ P value significant.

\begin{tabular}{|c|c|c|c|c|c|c|c|c|c|c|c|c|c|c|}
\hline \multirow[b]{2}{*}{ Hours } & \multicolumn{7}{|c|}{ Nishinda (V. negundo) Median \pm SD } & \multicolumn{7}{|c|}{ Garlic (A. sativum) Median \pm SD } \\
\hline & 24 & 48 & 72 & 96 & 120 & 144 & 168 & 24 & 48 & 72 & 96 & 120 & 144 & 168 \\
\hline LC50-value & $4.89 \pm 0.06$ & $4.48 \pm 0.09$ & $4.08 \pm 0.10$ & $3.73 \pm 0.10$ & $3.34 \pm 0.14$ & $2.46 \pm 0.28$ & $2.03 \pm 0.17$ & $5.33 \pm 0.07$ & $4.78 \pm 0.05$ & $4.32 \pm 0.07$ & $3.55 \pm 0.07$ & $3.22 \pm 0.09$ & $2.86 \pm 0.07$ & $2.20 \pm 0.18$ \\
\hline Slope & $9.98 \pm 0.91$ & $8.08 \pm 1.32$ & $5.31 \pm 1.34$ & $3.90 \pm 0.68$ & $3.08 \pm 0.57$ & $2.74 \pm 0.30$ & $2.23 \pm 0.32$ & $8.69 \pm 0.63$ & $7.06 \pm 0.54$ & $5.16 \pm 0.13$ & $3.91 \pm 0.18$ & $2.69 \pm 0.13$ & $2.30 \pm 0.20$ & $2.32 \pm 0.25$ \\
\hline Intercept & $-6.90 \pm 0.60$ & $-5.23 \pm 0.87$ & $-3.23 \pm 0.82$ & $-2.26 \pm 0.35$ & $-1.63 \pm 0.25$ & $-1.03 \pm 0.05$ & $-0.67 \pm 0.05$ & $-6.26 \pm 0.42$ & $-4.79 \pm 0.35$ & $-3.28 \pm 0.07$ & $-2.15 \pm 0.10$ & $-1.36 \pm 0.06$ & $-1.03 \pm 0.06$ & $-0.77 \pm 0.06$ \\
\hline$R$-value & 0.99 & 0.97 & 0.94 & 0.96 & 0.96 & 0.86 & 0.85 & 0.99 & 0.98 & 0.96 & 0.9 & 0.9 & 0.89 & 0.8 \\
\hline P-value & $<0.0001^{*}$ & $<0.0001$ * & $<0.0001$ * & $<0.0001$ * & $<0.0001 *$ & $0.0022 *$ & $0.0069 *$ & $<0.0001 *$ & $<0.0001$ * & $<0.0001 *$ & 0.0001 * & 0.0001 * & $0.0004^{*}$ & $0.0054 *$ \\
\hline t-test & $\mathrm{t}=4.76, \mathrm{df}=$ & $69, p<0.001$ & & & & & & & & & & & & \\
\hline
\end{tabular}


concentration of pesticides and mortality of nymph.

\section{$L C_{50}$ of NLE and GBE for mite adult}

Result according to probit analysis in Table 3 showed that mortality of $O$. coffeae adult was directly proportional to the time elapsed after treatment according to each enhancing concentration $(\mathrm{mg} / \mathrm{ml}) . \mathrm{LC}_{50}$ values for NLE on adults are 4.89, 4.48, 4.08, 3.73, 3.34, 2.46 and 2.03 $\mathrm{mg} / \mathrm{ml}$ and for GBE the $\mathrm{LC}_{50}$ values are $5.33,4.78,4.32$, $3.55,3.22,2.86$ and $2.20 \mathrm{mg} / \mathrm{ml}$ for $24,48,72,96,120$, 144 and $168 \mathrm{~h}$, respectively. Inclination value and upperlower confidence limits also decreased continuously with increasing time. In case of control, mortality was absent with respect to NLE and GBE. LC $_{50}$ values for NLE on adult is significantly lower than GBE $(\mathrm{t}=4.76, \mathrm{df}=69$, $\mathrm{p}<0.001)$, implying that NLE is more toxic to adult stage of mite than GBE. Correlation coefficient $(\mathrm{R})$ value for both green pesticides (NLE and GBE) indicate that there exists a positive correlation between pesticides concentrations and mite mortality which is statistically significant and this is also evident that increase in exposure time period to pesticides concentrations influences on mortality of mite.

\section{Discussion}

Application of chemical pesticides for controlling mites in tealeaves has been greatly diminished with the increase in global awareness (Roy et al. 2008). Out of 2400 plant species having the potential to subdue harmful creatures, about 100 species are utilized for controlling mites (Yang et al. 2007). Different researchers extensively studied the acaricidal effects of the extracts of these plants. The currently reliable and reproducible leaf disc bioassay derived by imitating the unique feeding habits of mites was established after many trials and errors (Mitra et al. 2015). The present bioassay was done by using tea leaf pieces dipped in different concentrations of nishinda leaf extract (NLE) and garlic bulb extract (GBE) on O. coffeae.

Garlic, a vegetable bulb, (A. sativum L.) belonging to family Amaryllidaceae, is well known for its acaricidal features (Attia et al. 2012). It is now termed as pesticide with minimum risk, which may provide a safe and feasible alternative to synthetic pesticides. It is easily available and cost effective to farmers (Su and Mulla 1998; Panella et al. 2005; Isman et al. 2008; Akyazi et al. 2018). It is well known that acaricidal effects of plant extracts are interconnected with their chemical compositions (Isman et al. 2001; Singh et al. 2001). A. sativum contains approximately 33 sulfur compounds (alliin, allicin, ajoene, allylpropyl disulfide, diallyl trisulfide, S-allylcysteine, vinyldithiines, $\mathrm{S}$-allylmercaptocystein, and others); minimum four times more sulphur than any other high-sulphur vegetables, inclusive of onions, broccoli, and cauliflower (Attia et al. 2012). It also consists of 17 amino acids (arginine and others), several enzymes (e.g., allinase, peroxidases, and myrosinase), and minerals (selenium, germanium, tellurium, and other trace minerals) (Newall et al. 1996; Omar and Wabel 2010). A large amount of organosulfur substances is responsible for toxic effects of A. sativum (Attia et al. 2011; Singh et al. 2001; Virtanen 1965; Roy et al. 2006; Mohammed 2013; Habashy et al. 2016; Wang et al. 2016). Binding of the garlic lectin to the glycosylated epithelial membrane of the insect gut is the predetermining factor for insecticidal activity, which has been revealed by the earlier reports (Bandyopadhyay et al. 2001). The present study showed that $\mathrm{LC}_{50}$ value was $5.33 \mathrm{mg} / \mathrm{ml}$ after $24 \mathrm{~h}$ of experiment against O. coffeae adult. $\mathrm{LC}_{50}$ values of $\mathrm{GBE}$ for nymphs and larva of red spider mite were observed to be $4.14 \mathrm{mg} / \mathrm{ml}$ and $3.60 \mathrm{mg} / \mathrm{ml}$, respectively, after 24 $\mathrm{h}$ of treatment reveals that nymphicidal and larvicidal activity were more effective than adulticidal $(5.33 \mathrm{mg} /$ $\mathrm{ml})$. The toxic effect of GBE was concentration and time dependent.

Five-leaved chaste tree nishinda (V. negundo) is a large aromatic shrubby plant belonging to family Lamiaceae, a willowy plant with a lofty grow in rainfed areas of West Bengal. V. negundo contains alkaloids, saponin and flavonoids revealed by TLC analysis (Khan et al. 2012). Better efficacy of $V$. negundo leaf extract on $T$. urticae has been reported by Yathiraj and Jagadish (1999). Aqueous leaf extracts (6\%) of V. negundo showed 76\% adult mortality of red spider mites, reported by Sugeetha and Srinivasa (1999), which strongly supports our present findings. We found that, the $\mathrm{LC}_{50}$ value of NLE for adult, nymph and larva stage of $O$. coffeae was $4.89,3.73$ and $3.04 \mathrm{mg} / \mathrm{ml}$, respectively, at $24 \mathrm{~h}$ of experiment, which indicate NLE is more potent than GBE. The difference in the application methods may cause differences between efficiency of extracts. Higher activity of methanol leaf extracts from $V$. negundo at 1-6\% concentration on III instar larvae of Spodoptera litura was recorded by Deepthy et al. (2010) which strongly corroborate our present findings.

\section{Conclusion}

Both NLE and GBE were found to possess significant acaricidal properties. Both the extracts were effective on the larva, nymph and adult stages of the red spider mite and when compared, NLE proved better among the two. NLE significantly had lower $\mathrm{LC}_{50}$ values than GBE on all the stages of mites with increasing time except the nymphal stage where, $\mathrm{LC}_{50}$ of both extracts were nearly equal. The study successfully underlines the acaricidal properties of both plants, but the experiments were done 
in-vitro condition. To establish both compounds as potent acaricides in future, the study needs to be extended to the tea plantations in Darjeeling.

\section{Acknowledgements}

We are thankful to the Principal, Barasat Govt. College, Kolkata for providing institutional research infrastructure. Financial support for this work was provided by grants from Department of Science \& Technology, Govt. of West Bengal [Sanction No.:1170(Sanc.)/ST/P/ S\&T/1G-4/2016, dated- 02.03.16] to Dr. Sanjoy Podder.

\section{References}

Akyazi R, Soysal M, Altunç EY, Lisle A, Hassan E, Akyol D (2018) Acaricidal and sublethal effects of tobacco leaf and garlic bulb extract and soft soap on Tetranychus urticae Koch (Acari: Trombidiformes: Tetranychidae). Syst Appl Acarol 23(10):2054-2069.

Attia S, Grissa KL, Mailleux AC, Lognay G, Euskin S, Mayoufi S, Hance T (2012) Effective concentrations of garlic distillate (Allium sativum) for the control of Tetranychus urticae (Tetranychidae). J Appl Entomol 136:302-312.

Bandyopadhyay S, Roy A, Das S (2001) Binding of garlic (Allium sativum) leaf lectin to the gut receptors of homopteran pests is correlated to its insecticidal activity. Plant Sci 161(5):1025-1033.

Banerjee P, Islam MM, Laha A, Biswas H, Saha, NC, Saha GK, Sarkar D, Bhattacharya S, Podder S (2020) Phytochemical analysis of mite-infested tea leaves of Darjeeling Hills, India. Phytochem Anal 31(3):277-286.

Bhujel A, Singh M, Choubey M, Singh M (2016) Pest and diseases management in Darjeeling tea. Int J Agric Sci Res 6(3):469-472.

Chen Z, Chen X (1989) An analysis of the world tea pest fauna. J Tea Sci 9(1):13-22.

Das GM (1959a) Bionomics of the tea red spider, Oligonychus coffeae (Nietner). Bull Entomol Res 50:265-274.

Das GM (1959b) Occurrence of red spider mite in relation to cultural practices in North- East India. Two and a Bud. 6(4):3-10.

Das GM (1960) Occurrence of red spider mite Oligonychus coffeae, (Nietner) on tea in North- East India in relation to pruning and defoliation. Bull Entomol Res 51:415-426.

Das GM (1965) Pest of Tea in North-East India and their Control. Tea Research Association, Tocklai, Assam, India.

Deepthy KB, Sheela MK, Jacob SS, Estelitta TJ (2010) Insecticidal and growth inhibitory action of Vitex negundo L. against Asian army worm, Spodoptera litura Fab. J Biopest 3(1):289-295.
Finney DJ (1971) Probit Analysis, 3rd ed. Cambridge University Press, Cambridge, UK.

Habashy MG, Al-Akhdar HH, Boraie DM, Ghareeb ZE (2016) Laboratory and semi-field evaluation of garlic aqueous extract as acaricide against two Tetranychid mites (Acari: Tetranychidae). J Plant Prot Path Mansoura Univ 7(10):623-628.

Ho SH, Koh L, Ma Y, Huang Y, Sim KY (1996) The oil of garlic, Allium sativum L. (Amaryllidaceae), as a potential grain protectant against Tribolium castaneum (Herbst) and Sitophilus zeamais Motsch. Postharvest Biol Technol 9:41-48.

Isman MB (2008) Botanical insecticides: for richer or poorer. Pest Manag Sci 64:8-11.

Isman MB, Wan AJ, Passreiter CM (2001) Insecticidal activity of essential oils to the tobacco cutworm Spodoptera litura. Fitoterapia 72:65-68.

Khan MA, Shah AH, Maqbol A, Khan N, Rahman ZU (2012) Miticidal activity of methanolic extract of Vitex negundo-lam against Sarcoptes scabiei in animals and man. J Anim Plant Sci 22(2 Suppl):102-107.

Mitra S, Gupta SK, Ghosh S (2015) Bio-efficacy of some green pesticides towards mortality and repellency against Petrobia harti Ewing (Acari: Tetranychidae) infesting medicinal weed, Oxalis corniculata L. (Oxalidaceae). Int J Appl Res 1(11):739-742.

Mohammed KS (2013) Antibacterial activity of Allium Sativum (Garlic) and identification of active compound by GC-MS analysis. Int J Pharm Bio Sci 4(4):1071-1076.

Newall CA, Anderson LA, Phillipson JD (1996) Herbal Medicines: A guide for health-care professionals. Vol IX. Pharmaceutical Press, London, UK.

Omar SH, Al-Wabel NA (2010) Organosulfur compounds and possible mechanism of garlic in cancer. Saudi Pharm J 18(1):51-58.

Panella NA, Dolan MC, Karcchesy JJ, Xiong Y, Peralta-Cruz J, Khasawneh MJ, Montenieri A, Maupin GO (2005) Use of novel compounds for pest control: insecticidal and acaricidal activity of essential oil components from heartwood of Alaska yellow cedar. J Med Entomol 42:352-358.

Roy A, Chakraborti D, Das S (2008) Effectiveness of garlic lectin on red spider mite of tea. J Plant Interact 3(3):157162.

Roy J, Shakleya DM, Callery PS, Thomas JG (2006) Chemical constituents and antimicrobial activity of a traditional herbal medicine containing garlic and black cumin. Afr J Trad CAM 3(2):1-7.

Singh UP, Prithiviraj B, Sharma BK, Singh M, Ray AB (2001) Role of garlic (Allium sativum L.) in human and plant diseases. Indian J Exp Biol 39:310-322.

Su T, Mulla MS (1998) Ovicidal activity of neem products (azadirachtin) against Culex tarsalis and Culex quinque- 
fasciatus (Diptera: Culcidae). J Am Mosq Control Assoc 14:204-209.

Sugeetha S, Srinivasa N (1999) Seasonal abundance of red spider mite, Tetranychus macfarlanei on okra varieties in Bangalore. J Acarol 15(1,2):10-14.

Uritu CM, Mihai CT, Stanciu GD, Dodi G, Alexa-Stratulat T, Luca A, Leon-Constantin MM, Stefanescu R, Bild V, Melnic S, Tamba BI (2018) Medicinal Plants of the Family Lamiaceae in Pain Therapy: A Review. Pain Res Manag 7801543.

Virtanen AI (1965) Studies on organic sulphur compounds and other labile substances in plants. Phytochemistry 4:207-228.
Wang X, Yang Y, Liu R, Zhou Z, Zhang M (2016) Identification of antioxidants in aged garlic extract by Gas Chromatography-Mass Spectrometry and Liquid Chromatography-Mass Spectrometry. Int J Food Prop 19:474-483.

Yang HZ, Li Q, Lei HD (2007) Research and application of botanical acaricides. Pesticide 46:81-85.

Yathiraj BR, Jagadish PS (1999) Plant extracts - future promising tools in the integrated management of spider mites, Tetranychus urticae (Acari: Tetranychidae). J Acarol 15(1-2):40-43. 